\title{
A Review of Patient and Provider Satisfaction with Telemedicine
}

\author{
Mary Nguyen $^{1}$ - Morgan Waller ${ }^{2}$ - Aarti Pandya ${ }^{1}$ - Jay Portnoy ${ }^{1,2}$ \\ Published online: 22 September 2020 \\ (C) Springer Science+Business Media, LLC, part of Springer Nature 2020
}

\begin{abstract}
Purpose of Review The purpose of this review is to describe the determinants of satisfaction with telemedicine (TM) and how they compare with in-person visits from both the perspective of patients and of providers.

Recent Findings The use of TM will expand only if patients and providers are at least as satisfied with it as they are with in-person visits. Since deviations from expected care can result in reduced satisfaction regardless of the quality of the visit or objective medical outcomes, it is important to understand and to help form those expectations when possible. Patients consistently report 95-100\% satisfaction rate with TM when compared with in-person appointments. They tend to cite the convenience of decreased travel times and costs as the main drivers for satisfaction with TM. Providers tend to be satisfied with TM if they have input into its development, there is administrative support, the technology is reliable and easy to use, and if there is adequate reimbursement for its use.

Summary Satisfaction with TM is necessary for adoption of this new technology. To improve satisfaction it is important to consider factors that drive it both for patients and for providers.
\end{abstract}

Keywords Telemedicine $\cdot$ Patient satisfaction $\cdot$ Provider satisfaction $\cdot$ Asthma

\section{Introduction}

According to the Office of the National Coordinator for Health Information Technology, telemedicine (TM) can be defined as "the use of electronic information and telecommunications technologies to support and promote long-distance clinical health care, patient and professional health-related education, public health and health administration" [1]. To be widely adopted, TM must compete favorably with in-person visits in a variety of objective measures including clinical outcomes [2], cost (both direct and indirect) [3], and availability $[4,5 \cdot \bullet]$. In addition, patients and providers need to be at least as satisfied with their telehealth experience as they are with in-person visits. If this is not achieved, they both will

This article is part of the Topical Collection on Telemedicine and Technology

Jay Portnoy

jportnoy@cmh.edu

1 Section of Allergy, Asthma \& Immunology, Children's Mercy Hospital, 2401 Gillham Road, Kansas City, MO 64108, USA

2 Division of Telemedicine, Children's Mercy Hospital, Kansas City, MO, USA refuse to use TM and as a result, adoption of the new technology will languish.

Objectively, use of TM for patient care can improve access by connecting patients to providers while reducing the need for travel and its associated expenses and inconvenience. Weibel et al. studied 423 patients at 13 military bases across Europe and found that patients saved an average of $\$ 485$ in travel expenses, 438 driving miles, and 2.3 days of work or school per visit by using TM to see a provider. TM can also improve access to care for patients in underserved areas of rural and urban communities by reducing geographical distance barriers. In addition, providers who are restricted from going to a medical clinic for health reasons or to avoid infection can continue to see patients if they use TM. Yet if patients and providers are unsatisfied with TM, they may prefer to suffer the inconvenience and unavailability of in-person care rather than be subjected to a bad experience.

According to a 2016 AMA survey of practices that use TM by specialty, an average of $15 \%$ of practices in all specialties use TM for visits between providers and patients [6]. Yet only $6 \%$ of allergy practices use TM, making allergy/immunology the specialty with the lowest adoption rate of any of the surveyed specialties, though this may be changing due to COVID-19. While many barriers to the use of TM are present, the degree of satisfaction with the experience is clearly 
important. The purpose of this review is to describe the determinants of satisfaction with TM and how they compare with in-person visits from both the perspective of patients and of providers.

\section{Measurement of Satisfaction}

Conceptually, six dimensions need to be considered when measuring quality of care. These include the overall satisfaction with care, who the stakeholders are, the type of care, type of system used, the context in which the care is delivered, and methodologies (Table 1) [7]. The dimensions of overall satisfaction that likely are influenced using TM include the technology's perceived usefulness, its ease of use, and its reliability. Stakeholders that need to be considered include the providers, the patients, and the administrators who manage a TM system. The type of care dimension refers to the medical specialty (e.g., allergy, cardiology, mental health) and the type of service provided (e.g., ongoing care, consultation, triage). Systems used to implement TM include synchronous visits (e.g., video conferencing, facilitated visits), asynchronous TM (e.g.: store and forward, remote patient monitoring), or use of mobile devices or web-based tools. The context

Table 1 Dimensions to consider when measuring satisfaction [7]

\begin{tabular}{|c|c|}
\hline Dimension & Examples \\
\hline Overall satisfaction with care & $\begin{array}{l}\text {-Usefulness } \\
\text { - Ease of use } \\
\text { - Reliability }\end{array}$ \\
\hline Stakeholders & $\begin{array}{l}\text {-Providers } \\
\text {-Patients } \\
\text {-Administrators }\end{array}$ \\
\hline Type of care & $\begin{array}{l}\text {-Medical specialty (e.g., allergy } \\
\text { cardiology, mental health) } \\
\text {-Type of service provided } \\
\text { - Ongoing care } \\
\text {-Consultation } \\
\text {-Triage }\end{array}$ \\
\hline Type of system used & $\begin{array}{l}\text {-Synchronous visits } \\
\text {-Direct to consumer } \\
\text { - Facilitated visits } \\
\text {-Asynchronous visits } \\
\text { - Store and forward } \\
\text { - Remote patient monitoring } \\
\text { Mobile devices } \\
\text {-Web-based }\end{array}$ \\
\hline Context in which care is delivered & $\begin{array}{l}\text {-Medical office } \\
\text {-Patient home } \\
\text {-School } \\
\text {-Workplace }\end{array}$ \\
\hline Methodologies & $\begin{array}{l}\cdot \text { In-person } \\
\text {-By mail } \\
\text { •Web-based } \\
\text {-Telephone }\end{array}$ \\
\hline
\end{tabular}

dimension accounts for where the visit occurs (e.g., physician's office, patient home, school, workplace). The methodology dimension is determined by how satisfaction is measured (e.g., in-person, by mail, web-based, telephone). A system that fails to meet the expectations considered by these dimensions is unlikely to be satisfying and therefore is unlikely to be adopted by the stakeholders.

Measurement of satisfaction can be either formative (i.e., improves clinical services using an iterative process that maximizes the measurement) or summative (i.e., judges the quality of clinical care). One summative reason for its measurement is to compare satisfaction with two different types of care delivery such as telemedicine vs. in-person care among various stakeholders such as providers and patients. This is important because adoption of TM hinges critically on whether patients and providers are satisfied with the care; they either receive or deliver when using it. If either group is not satisfied with telemedicine, they can always revert to in-person visits.

\section{Patient Satisfaction}

Originally, patient satisfaction was measured because it was believed that satisfied patients were more likely to be compliant with treatment and therefore would have improved outcomes [8]. The use of patient satisfaction surveys subsequently has become commercialized, and now it often is used to judge the quality of care given by providers and hospitals rather than to help form it. In some cases, patient satisfaction also is used to determine payment to hospitals and to providers even though it is not clear that satisfaction correlates with improved clinical outcomes. As a result, attempts to improve satisfaction tend to focus on patient perceptions related to the items used to measure it regardless of actual outcomes.

The empirical dimensions of a patient's view of quality were identified in a meta-analysis of 221 studies of patient satisfaction [9•]. These can be summarized as shown in Table 2. While each dimension is important, several are likely to be favorably influenced by use of TM including physical facilities (the patient can be seen in their home), continuity of care (the same provider can be seen regardless of where they are located), access (less distance needs to be traveled), cost (no need for gas, meals, hotels), and bureaucracy (long lines and waiting rooms are avoided). Dimensions for which an inperson visit may favorably influence satisfaction include humaneness (the personal touch is present) and the amount of information exchanged (including body language, the ability for more back and forth discussion, and immediate delivery of handouts). Dimensions for which it is unclear whether inperson or TM visits have an advantage include technical competence of the provider and patient, patient outcomes, and attention to psychosocial problems. The latter is particularly interesting since some patient may feel more comfortable 
Table 2 Empirical dimensions of patients' perception of quality of care with examples [9॰] and the author's impression of the likely effect of telemedicine on patient satisfaction

\begin{tabular}{|c|c|c|}
\hline $\begin{array}{l}\text { Dimension of perceived } \\
\text { quality of care }\end{array}$ & Example(s) & $\begin{array}{l}\text { Likely effect of } \\
\text { telemedicine }\end{array}$ \\
\hline Overall satisfaction & This is a composite of the following examples. & Unknown \\
\hline Humaneness & The "personal touch" is present with in-person visits & Reduced \\
\hline Technical competence & $\begin{array}{l}\text { The provider can diagnose and treat the patient's medical } \\
\text { condition }\end{array}$ & Unknown \\
\hline Outcome & The patient's condition improves & Unknown \\
\hline Physical facilities & The patient can be seen in their home & Improved \\
\hline Continuity of Care & $\begin{array}{l}\text { Patients can see same provider regardless of where they, or the } \\
\text { provider, are located }\end{array}$ & Improved \\
\hline Access & $\begin{array}{l}\text { Less distance may need to be traveled. This depends on how } \\
\text { far the patient needs to travel. }\end{array}$ & Improved \\
\hline Amount of information & $\begin{array}{l}\text { In addition to verbal information, includes body language, the } \\
\text { ability for back and forth discussion and immediate delivery } \\
\text { of handouts }\end{array}$ & Reduced \\
\hline Cost & Reduced need for gas, meals, hotels if travel is needed & Improved \\
\hline Bureaucracy/Organization & Parking, long lines and waiting rooms can be avoided. & Improved \\
\hline $\begin{array}{l}\text { Attention to psychosocial } \\
\text { problems }\end{array}$ & $\begin{array}{l}\text { Patients may prefer an in-person or TM visit when discussing } \\
\text { sensitive issues. }\end{array}$ & Unknown \\
\hline
\end{tabular}

discussing sensitive issues in-person while others may find comfort discussing such issues from behind the barrier that a video screen provides. Overall, it is not clear that in-person visits offer an obvious advantage over TM when a combination of these dimensions is considered.

While satisfaction is based largely on the experience that providers and patients have with the actual clinical encounter, expectations about that experience can lead to varying degrees of satisfaction even if the objective encounter is held constant. Thompson described four types of expectations that commonly influence the experience that patients have with medical care: (1) ideal, (2) predicted, (3) normative, and (4) unformed expectations (Table 3) [10॰]. The Ideal expectation is driven by the patient's belief of what a perfect medical encounter should consist of, as exemplified by the 1970s TV show Marcus Welby MD in which a friendly and wise family doctor devotes $100 \%$ of his attention to a single patient until all issues are resolved. Who does not want that type of experience? Predicted expectations are driven by a patient's realistic understanding of how medical visits are conducted, which is likely to result from their personal experience or from the reported experiences of others. Normative expectations represent what the patient believes should happen during the visit as exemplified by another TV series House in which a serious condition can be cured only if the right doctor orders a specific test to identify the patient's problem leading to a cure. Unformed expectations occur when the patient either does not have any expectations or they take for granted that whatever care they get is what they should get. Deviations from expected care can result in reduced satisfaction regardless of the quality of the visit or objective medical outcomes.

\section{Synchronous Visits}

In 2016, a study of adult patients using telemedicine in a MinuteClinic found that $98 \%$ of patients were very satisfied with telemedicine [11]. In a Norwegian study of 402 patients with headaches, the long-term satisfaction with telemedicine was $85.5 \%$ as compared with $88.1 \%$ for patients in an inperson group [12]. According to another survey by Taylor et al., most of 3512 rural patients were comfortable or were at least equivocal with the use of telemedicine [13••]. In fact, patients consistently report $95-100 \%$ satisfaction rate with TM when compared with in-person appointments [11].

This tendency to be satisfied with TM was further confirmed in a systematic review of patient satisfaction with visits done by TM compared with in-person visits that included 93
Table 3 Four types of expectations that commonly influence the experience that patients have with medical care $[10 \bullet$. Deviations from expected care can result in reduced satisfaction regardless of the quality of the visit

\begin{tabular}{|c|c|c|}
\hline Expectation & Description & Example(s) \\
\hline Ideal & What a "perfect" medical encounter should consist of & Marcus Welby MD \\
\hline Predicted & $\begin{array}{l}\text { Realistic understanding of how medical visits are } \\
\text { conducted }\end{array}$ & $\begin{array}{l}\text { Previous experience with medical } \\
\text { care }\end{array}$ \\
\hline Normative & What the patient believes should happen during the visit & Dr. House \\
\hline Unformed & Whatever care they get is what they should get & Passive acceptance of care received \\
\hline
\end{tabular}


studies. Satisfaction with TM was as good as, or better than, satisfaction with in-person visits and was consistently $>80 \%$ and often was reported to be nearly $100 \%$ [14].

Patients and parents tend to cite the convenience of decreased travel times and costs as the main drivers for satisfaction with TM [15]. A recent report by Mustafa was consistent with this, finding that $89 \%$ of patients seen in by an allergy service during COVID-19 were as satisfied or more satisfied with TM than they were with in-person visits [16••]. Other benefits of TM visits cited by patients include less time away from school and work, a decrease in wait time, and increased access to see pediatric specialists [17].

Non-medical behaviors may affect patient satisfaction with a TM encounter [18]. In one study it was noted that eye contact was interrupted while providers referred to the EMR during TM visits. Since patients did not always understand what the provider was looking at, this could have adversely affected the perceived quality of the visit.

An analysis of 28,222 encounters between 24,040 patients and 277 primary care physicians was performed in a direct-toconsumer program. Respiratory infections were diagnosed in $35 \%$ of encounters and $69 \%$ resulted in a prescription. Patients rated their provider 5 stars (out of 5) $85 \%$ of the time, though this satisfaction was highly correlated with receipt of a prescription and with provision of drug coupons. Had they not used telemedicine, $43 \%$ of patients reported they would have used an urgent care clinic, $29 \%$ would have gone to the doctor's office, $15 \%$ would have done nothing, and $6 \%$ would have gone to the emergency department [19].

Satisfaction with TM also is high for hospitalized patients. A study conducted to assess the satisfaction of penicillin allergy visits that utilized TM. In this study, hospitalized patients with a history of penicillin allergy who were being treated with systemic antibiotics were identified. Those who agreed to participate underwent skin testing under the guidance of a physician assistant. Subsequently, a TM visit was conducted with a physician and if patients had negative skin tests they were transitioned to a Beta-lactam antibiotic. Use of this methodology helps reduce hospital costs by $\$ 30,000$. A total of 49 patients were surveyed on satisfaction afterwards, and $90 \%$ indicated a high level of satisfaction [20].

Finally, in a DTC study of diabetes care using an iPad with Facetime, $65 \%$ reported being satisfied and $76 \%$ felt that the visits improved their diabetes care. The providers in a multidisciplinary team experienced high amounts of satisfaction initially, but this decreased over time [21].

\section{Asynchronous Visits}

In a study of asynchronous TM involving either interpretation of EKGs or delivery of lab results involving 564 patients, the perceived quality of care both by patients and healthcare staff found a clear perception of improved quality of service both by patients and by healthcare professionals [22]. Determinants of this included reduced need for travel to another municipality (34\% before TM, $11 \%$ with TM) and wait time for the test to be performed (66\% within a week before TM, $94 \%$ with TM). In addition, the waiting time to receive test results was less ( $71 \%$ took $>15$ days before TM, $25 \%$ with TM). Overall, $73 \%$ found the system to be easy to use and only $2 \%$ found it hard to use. When compared with traditional testing, 38\% found that use of asynchronous TM was improved and 60\% found it to be greatly improved while only $2 \%$ felt that they were the same and nobody felt that it was worse.

A controlled study compared satisfaction with dermatology care using in-person visits, asynchronous TM (store-and-forward), and synchronous TM using two types of video. The patients ranked their preference after experiencing all methods and the dermatologists ranked their preferences at the end of the study. In-person examinations were preferred both by patients and by dermatologists; however, patients had no preference between store-and-forward workups or live interactive video. Dermatologists were also divided regarding preference for store-and-forward or video [23]. A systematic review of satisfaction with teledermatology found that $96 \%$ of patients and $82 \%$ of providers were satisfied with store-and-forward in which images of rashes were sent to a server for subsequent review by providers [24].

\section{Provider Satisfaction}

While most studies of TM have focused on patient satisfaction, provider satisfaction (both referring and performing providers) has been studied less frequently. Yet, provider satisfaction is a critical determinant of whether TM will be used to see patients. A framework for studying provider satisfaction was developed using a group of 12 osteopathic and allopathic physicians. The framework included 5 components of satisfaction with care delivery using TM: professional demographics, care settings, motivations, experiences, and overall satisfaction $[25 \bullet \bullet]$.

In one study, the perception that providers had towards a TM program was improved if they were involved in developing it [26]. In another study of 7 TM networks affiliated with academic health centers, 68 providers were satisfied with using TM in proportion to how much they participated in its design. In addition, providers who participated were more likely to perceive that their patients were satisfied, and they were likely to use it more frequently. Another study found that the perceived usefulness of TM correlated with the likelihood that providers would use it [27]. In addition, providers who tended to be innovative were more likely to use TM regardless of how easy it was to use. In yet another study, the tendency to be self-sufficient corresponded with the tendency to use TM 
[28]. In other words, disincentives to use of TM such as perceived difficulty to use, lack of accessibility, and reduced incentives such as payment can be overcome if a provider likes using new, innovative technologies and devices and if they are able to design the way in which they are used.

An on-line survey followed by a focus group of 57 dermatology providers and nurses who did TM and 42 who did not do TM found that satisfaction was higher in the TM group if TM was supported by opinion leaders, there were sufficient resources available, and if the style of encounters was complementary to the patient context [29]. In addition, TM providers tended to report having good working relationships and communication with staff more often than providers who did not use TM. They also tended to agree that they understood how to use the digital equipment, it was easy to use, and that it was reliable. Patients who were seen by those providers reported feeling comfortable with technology in genera including use of social media, e-learning, and technology for communicating to others.

To be successful, the technology needs to work, and providers need to be trained to see patients using TM [30]. In addition, appropriate providers need to be selected and patients need to be prepared for a virtual encounter. According to patients and providers in one study, providers are more likely to be successful at using TM if they are flexible and tolerate, creative, and they need to have problem solving skills. It was also noted that seasoned clinicians tend to do better since they already have developed medical skills and only need to focus on using the new technology. Younger providers tend to do better if they are coached by more seasoned providers.

A German study of TM found greater utilization of TM among specialists than generalists and that providers in larger facilities tended to use it more than those in smaller ones. This was felt to be due to better standardization, documentation, and available support systems to support TM in the larger facilities [31].

For TM to be used successfully, it is necessary for there to be effective organization, reliable technology, adequate financing, regulations that support its use, and acceptance by providers and patients [32]. Though each of these is essential for success, a recent study found that acceptance was the most important aspect with reliable technology a close second. If providers and patients do not want to use TM, it is not going to succeed. In a study of 36 Australian TM programs, provider acceptance was the most important factor determining success. In fact, high acceptance could overcome other obstacles such as low demand, technology problems, and inadequate financing [33].

Another study involving 5 internal medicine providers compared satisfaction with patient care when they were seen by TM or in-person [34]. These providers tended to be less satisfied with TM encounters because of perceived reduced doctor-patient communication. Most felt it was easier to engage in small talk with in-person visits, and therefore, patient understanding was better. Despite this, the patients generally were satisfied with the TM experience.

The primary benefit of TM is convenience to patients in terms of distance traveled and time away from work and school [35]. Providers also benefit in that they do not have to travel to remote locations to see their patients. This becomes an incentive to embrace the new technology. Another benefit is reducing the risk of infection from both parties which can be crucial in a circumstance where one or both parties are immunocompromised and particularly during the current COVID19 pandemic.

Providers who deliver care via TM need to feel comfortable giving up some control over the visit while retaining enough to provide patient care. Many providers might find this difficult. To create satisfaction with patient care using TM, it is important that providers feel that they can maintain their status as a patient's medical caregiver. It also helps for providers to keep their expectations about how TM will work to a minimum. That way use of TM will be seen as an opportunity to improve patient care rather than as a threat to their role.

Another study evaluated provider satisfaction with TM services and technology acceptance using a structured questionnaire. Perceived ease of use and usefulness of TM services were found to dominantly influence provider satisfaction. This study contributes to empirical knowledge by identifying the vital predictive factors affecting telemedicine services satisfaction among providers [36•].
Table 4 Recommendations for improving provider and patient satisfaction with Telemedicine

\begin{tabular}{|c|c|}
\hline Improved provider satisfaction & Improved patient satisfaction \\
\hline \multirow{2}{*}{$\begin{array}{l}\text {-Involve providers in the design of the } \\
\text { telemedicine program }\end{array}$} & -Promote realistic expectations before the visit takes place \\
\hline & \multirow{2}{*}{$\begin{array}{l}\text {-Use satisfaction surveys formatively to improve the experience of } \\
\text { telemedicine }\end{array}$} \\
\hline -Administrative support for use of TM & \\
\hline -Easy to use, reliable technology & -Easy to use, reliable technology \\
\hline $\begin{array}{l}\text {-Involve appropriate providers who are } \\
\text { flexible, enjoy innovation }\end{array}$ & $\begin{array}{l}\text {-Involve appropriate patients who are adaptable and who welcome } \\
\text { the convenience of the new technology }\end{array}$ \\
\hline $\begin{array}{l}\text {-Adequate reimbursement for care } \\
\text { delivered via TM }\end{array}$ & \\
\hline
\end{tabular}


A study of satisfaction among 161 providers and 201 patients using video TM for treatment of depression found a mean score on a 3-question survey of 9.17 for providers and 9.70 for patients which was statistically significant [37].

\section{Conclusions}

Extensive studies have demonstrated a high level of satisfaction with TM visits from patients and providers. Table 4 offers several suggestions for improving satisfaction with the TM experience for both groups. By increasing satisfaction with $\mathrm{TM}$, at least to the level of satisfaction with in-person visits, use of TM likely will continue to flourish.

\section{Compliance with Ethical Standards}

Conflict of Interest Mary Nguyen MD has no relevant conflicts to report.

Morgan Waller RN has no relevant conflicts to report.

Aarti Pandya MD has no relevant conflicts to report.

Jay Portnoy MD has no relevant conflicts to report.

The authors declare no conflicts of interest relevant to this manuscript.

Human and Animal Rights and Informed Consent This article does not contain any studies with human or animal subjects performed by any of the authors.

\section{References}

Papers of particular interest, published recently, have been highlighted as:

- Of importance

•- Of major importance

1. ONC. Telemedicine and Telehealth. Washington, DC: The Office of the National Coordinator for Health Information Technology; 2018. https://www.healthit.gov/topic/health-it-initiatives/ telemedicine-and-telehealth

2. Portnoy JM, Waller M, De Lurgio S, Dinakar C. Telemedicine is as effective as in-person visits for patients with asthma. Ann Allergy Asthma Immunol. 2016;117(3):241-5. https://doi.org/10.1016/j. anai.2016.07.012.

3. Delgoshaei B, Mobinizadeh M, Mojdekar R, Afzal E, Arabloo J, Mohamadi E. Telemedicine: A systematic review of economic evaluations. Med J Islam Repub Iran. 2017;31:113. https://doi. org/10.14196/mjiri.31.113.

4. Dehours E, Valle B, Bounes V, Girardi C, Tabarly J, Concina F, et al. User satisfaction with maritime telemedicine. J Telemed Telecare. 2012;18(4):189-92. https://doi.org/10.1258/jtt.2012. 110910.

5.・ Chongmelaxme B, Lee S, Dhippayom T, Saokaew S, Chaiyakunapruk N, Dilokthornsakul P. The effects of telemedicine on asthma control and patients' quality of life in adults: a systematic review and meta-analysis. J Allergy Clin Immunol Pract. 2019;7(1):199-216 e11. https://doi.org/10.1016/j.jaip.2018.07. 015 A systematic review of telemedicine for treatment of patients with asthma and allergic disorders.
6. Kane CK, Gillis K. The use of telemedicine by physicians: still the exception rather than the rule. Health Aff (Millwood). 2018;37(12): 1923-30. https://doi.org/10.1377/hlthaff.2018.05077.

7. Garcia R, Adelakun O. A conceptual framework and pilot study for examining telemedicine satisfaction research. J Med Syst. 2019;43(3):51. https://doi.org/10.1007/s10916-019-1161-4.

8. Junewicz A, Youngner SJ. Patient-satisfaction surveys on a scale of 0 to 10: improving health care, or leading it astray? Hast Cent Rep. 2015;45(3):43-51. https://doi.org/10.1002/hast.453.

9. Hall JA, Dornan MC. Meta-analysis of satisfaction with medical care: description of research domain and analysis of overall satisfaction levels. Soc Sci Med. 1988;27(6):637-44. https://doi.org/10. 1016/0277-9536(88)90012-3 A meta-analysis of 221 studies of patient satisfaction that identified the empirical dimensions of a patient's view of quality.

10. Thompson AG, Sunol R. Expectations as determinants of patient satisfaction: concepts, theory and evidence. Int J Qual Health Care. 1995;7(2):127-41. https://doi.org/10.1093/intqhe/7.2.127 Expectations that patients tend to have for clinical care. Deviations from these can adversely effect satisfaction with care.

11. Polinski JM, Barker T, Gagliano N, Sussman A, Brennan TA, Shrank WH. Patients' satisfaction with and preference for telehealth visits. J Gen Intern Med. 2016;31(3):269-75. https://doi.org/10. 1007/s11606-015-3489-x.

12. Muller KI, Alstadhaug KB, Bekkelund SI. Headache patients' satisfaction with telemedicine: a 12-month follow-up randomized noninferiority trial. Eur J Neurol. 2017;24(6):807-15. https://doi.org/ 10.1111/ene.13294

13.• Taylor L, Waller M, Portnoy JM. Telemedicine for allergy services to rural communities. J Allergy Clin Immunol Pract. 2019;7(8): 2554-9. https://doi.org/10.1016/j.jaip.2019.06.012 A recent review of satisfaction with telemedicine in rural communities.

14. Williams TL, May CR, Esmail A. Limitations of patient satisfaction studies in telehealthcare: a systematic review of the literature. Telemed J E Health. 2001;7(4):293-316. https://doi.org/10.1089/ 15305620152814700

15. Kruse CS, Krowski N, Rodriguez B, Tran L, Vela J, Brooks M. Telehealth and patient satisfaction: a systematic review and narrative analysis. BMJ Open. 2017;7(8):e016242. https://doi.org/10. 1136/bmjopen-2017-016242.

16.• Mustafa SS, Yang L, Mortezavi M, Vadamalai K, Ramsey A. Patient satisfaction with telemedicine encounters in an allergy and immunology practice during the coronavirus disease 2019 pandemic. Ann Allergy Asthma Immunol. 2020. https://doi.org/10.1016/j. anai.2020.06.027 A recent paper that describes satisfaction with allergy services delived via telemedicine.

17. Taylor L, Capling H, Portnoy JM. Administering a telemedicine program. Curr Allergy Asthma Rep. 2018;18(11):57. https://doi. org/10.1007/s11882-018-0812-8.

18. Bulik RJ. Human factors in primary care telemedicine encounters. J Telemed Telecare. 2008;14(4):169-72. https://doi.org/10.1258/jtt. 2007.007041.

19. Martinez KA, Rood M, Jhangiani N, Kou L, Rose S, Boissy A, et al. Patterns of use and correlates of patient satisfaction with a large nationwide direct to consumer telemedicine service. J Gen Intern Med. 2018;33(10):1768-73. https://doi.org/10.1007/ s11606-018-4621-5.

20. Staicu ML, Holly AM, Conn KM, Ramsey A. The use of telemedicine for penicillin allergy skin testing. J Allergy Clin Immunol Pract. 2018;6(6):2033-40. https://doi.org/10.1016/j.jaip.2018.04. 038.

21. Robinson MD, Branham AR, Locklear A, Robertson S, Gridley T. Measuring satisfaction and usability of FaceTime for virtual visits in patients with uncontrolled diabetes. Telemed J E Health. 2016;22(2):138-43. https://doi.org/10.1089/tmj.2014.0238. 
22. von Wangenheim A, de Souza Nobre LF, Tognoli H, Nassar SM, Ho K. User satisfaction with asynchronous telemedicine: a study of users of Santa Catarina's system of telemedicine and telehealth. Telemed J E Health. 2012;18(5):339-46. https://doi.org/10.1089/ tmj.2011.0197.

23. Marchell R, Locatis C, Burgess G, Maisiak R, Liu WL, Ackerman M. Patient and provider satisfaction with teledermatology. Telemed J E Health. 2017;23(8):684-90. https://doi.org/10.1089/tmj.2016.0192.

24. Mounessa JS, Chapman S, Braunberger T, Qin R, Lipoff JB, Dellavalle RP, et al. A systematic review of satisfaction with teledermatology. J Telemed Telecare. 2018;24(4):263-70. https:// doi.org/10.1177/1357633X17696587.

25.• Law T, Cronin C, Schuller K, Jing X, Bolon D, Phillips B. Conceptual Framework to Evaluate Health Care Professionals' Satisfaction in Utilizing Telemedicine. J Am Osteopath Assoc. 2019;119(7):435-45. https://doi.org/10.7556/jaoa.2019.080 A framework of 5 components of satisfaction with care delivery using TM: professional demographics, care settings, motivations, experiences, and overall satisfaction.

26. Demiris G. Examining health care providers' participation in telemedicine system design and implementation. In: AMIA Annual Symposium proceedings AMIA Symposium; 2006. p. 906.

27. Huang J-C. Innovative health care delivery system - a questionnaire survey to evaluate the influence of behavioral factors on individuals' acceptance of telecare. Comput Biol Med. 2013;43(4):2816. https://doi.org/10.1016/j.compbiomed.2012.12.011.

28. Rho MJ, Choi IY, Lee J. Predictive factors of telemedicine service acceptance and behavioral intention of physicians. Int J Med Inform. 2014;83(8):559-71. https://doi.org/10.1016/j.ijmedinf. 2014.05.005.

29. Ariens LF, Schussler-Raymakers FM, Frima C, Flinterman A, Hamminga E, Arents BW, et al. Barriers and facilitators to eHealth use in daily practice: perspectives of patients and professionals in dermatology. J Med Internet Res. 2017;19(9):e300. https://doi.org/10.2196/jmir.7512.

30. LeRouge C, Garfield MJ, Collins RW. Telemedicine: technology mediated service relationship, encounter, or something else? Int J
Med Inform. 2012;81(9):622-36. https://doi.org/10.1016/j. ijmedinf.2012.04.001.

31. Dünnebeil S, Sunyaev A, Blohm I, Leimeister JM, Krcmar H. Determinants of physicians' technology acceptance for e-health in ambulatory care. Int J Med Inform. 2012;81(11):746-60. https:// doi.org/10.1016/j.ijmedinf.2012.02.002.

32. Broens TH, Huis in't Veld RM, Vollenbroek-Hutten MM, Hermens HJ, van Halteren AT, Nieuwenhuis LJ. Determinants of successful telemedicine implementations: a literature study. J Telemed Telecare. 2007;13(6):303-9. https://doi.org/10.1258/ 135763307781644951.

33. Wade VA, Eliott JA, Hiller JE. Clinician acceptance is the key factor for sustainable telehealth services. Qual Health Res. 2014;24(5):682-94. https://doi.org/10.1177/1049732314528809.

34. Liu X, Sawada Y, Takizawa T, Sato H, Sato M, Sakamoto H, et al. Doctor-patient communication: a comparison between telemedicine consultation and face-to-face consultation. Internal Med (Tokyo, Japan). 2007;46(5):227-32.

35. Buck S. Nine human factors contributing to the user acceptance of telemedicine applications: a cognitive-emotional approach. J Telemed Telecare. 2009;15(2):55-8. https://doi.org/10.1258/jtt. 2008.008007.

36. Kissi J, Dai B, Dogbe CS, Banahene J, Ernest O. Predictive factors of physicians' satisfaction with telemedicine services acceptance. Health Informatics J. 2019;1460458219892162. https://doi.org/10. $1177 / 1460458219892162$ Factors that are predictive of physicians' satisfaction with and acceptance of telemedicine services.

37. Christensen LF, Gildberg FA, Sibbersen C, Skjoeth MM, Nielsen CT, Hansen JP. Disagreement in satisfaction between patients and providers in the use of videoconferences by depressed adults. Telemed J E Health. 2019;26:614-20. https://doi.org/10.1089/tmj. 2019.0055 .

Publisher's Note Springer Nature remains neutral with regard to jurisdictional claims in published maps and institutional affiliations. 